\title{
In harmony with nature - the Suckling Elephant House of Malaysia
}

\author{
A. Bahauddin \& A. Abdullah \\ School of Housing, Building \& Planning, \\ Universiti Sains Malaysia, Penang, Malaysia
}

\begin{abstract}
As the world cries about the global warming phenomenon, designers are looking at ways of constructing better living units. One way of dealing with this problem is by looking at the architecture of the past. This paper explores the traditional Malay architecture of the Suckling Elephant House mainly found in the northern part of Malaysia. This type of house is currently dwindling in number. Steps are required to document this house due to its rich cultural, social and environmental attributes related to its simple timber construction and surroundings. The methodology of this research involves thorough literature review supported by surveys, measured drawings, interviews and visual data collection. History has taught us a lot of lessons through philosophies, customs and rituals; the Suckling Elephant House is no exception. This Malay vernacular architecture has shown many ways of designing a house that is suited to the climate, weather and the environment. Above all, the early builders knew how to construct a habitation for comfort that serves its function as a place for shelter from the elements and safety from wild animals. The Suckling Elephant House although featuring a humble appearance, is rich with traditions that are almost spiritual. It manages to create a more meaningful space for habitation. It is a clear indication that the constructions, the embellishments and the space planning that make up the house strengthen the spiritual being right from the exterior to the interior living space. The history and the heritage of this house must be upheld although Malaysia's modernisation cries for a better outlook of houses. Learning from the Suckling Elephant House's history and customs that are associated with it will revive the knowledge in designing and constructing houses in a tropical climate for the comfort of the inhabitants.
\end{abstract}

Keywords: traditional, spiritual, customs, space planning, embellishments. 


\section{Introduction}

The suckling elephant house is one form of traditional Malay houses that began the evolution of house design in Malaysia (figure 1). It is also an indicator of a regional style of a village house (figure 2). Little is known about the suckling elephant house for the information about this piece of architecture is limited or almost non-existent. It is a familiar form of a village house in the northern region of the Peninsular Malaysia; however, this style of architecture has long seen its glory days [1] It is facing extinction coupled by the development of modern housing that moves away from any traditional form of house design. The gajah menyusu house or the suckling elephant house (figure 3) is derived from the act of an elephant suckling its young. The formation of the suckling elephant house (figure 4) is recognised by the shape of its roof whereby the form of the main house is higher than the roof of the veranda [2]. Hence, the structure is seen as similar to a baby elephant being fed by its mother. Information that is available

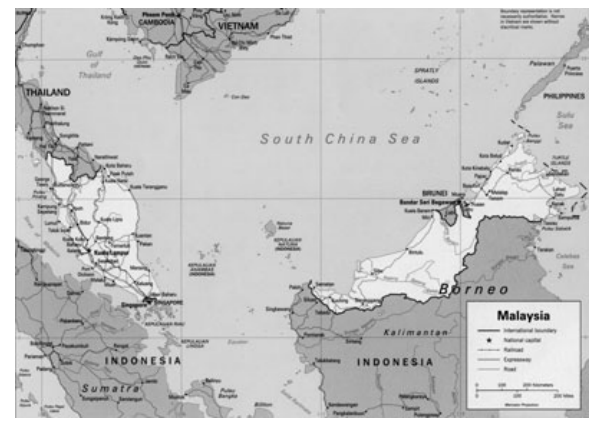

Figure 1: $\quad$ Map of Malaysia and southeast Asia region.

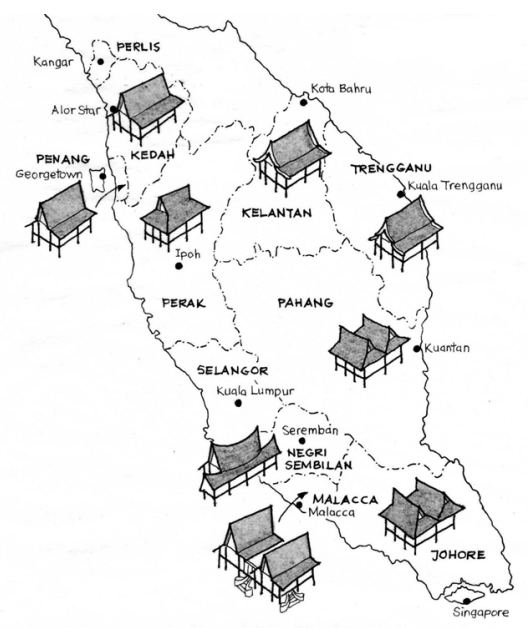

Figure 2: Regional traditional Malay house location. 


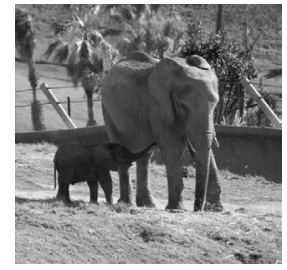

Figure 3: Suckling baby elephant.

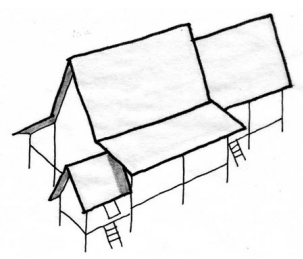

Figure 4: The suckling elephant house with its roof character.

on the suckling elephant house talks only about the architecture with little emphasis on interior space planning, the detail embellishments and the philosophy or cultural relationships that will explain how this style of architecture came onto the scene. Not much research has been done into the understanding of the philosophy of the suckling elephant house in the northern region part of the Peninsular Malaysia. The region comprises particularly of Penang, Kedah and Perlis states sees the dwindling in numbers of this type of traditional Malay house due to rapid housing development and new technology in construction materials.

Current information available only points out the basic data and neglects the cultural and social aspects in detail. This is regarding the cultural influences particularly of the Malay culture, the philosophy and the 'whys' of the design was created as well as the environment that this architecture style was erected within its perimeters [3]. Every space designed for this house carries its own meaning and the space planning involved speaks of deeper cultural background. The rituals, customs and traditions that are associated with the suckling elephant present a new understanding and meaning to the interior space planning and the display of the detail embellishments. The detail embellishments relate to the decoration such a carving, air vent, interior finishes and many more detailed embellishments to the house. The 'slow death' that this style of architecture is facing has so far been ignored and overlooked in the name of development. Many people do not understand the importance of the elephant suckling house in terms of its design and knowledge that it imparts on its association with sustainable design, the current hot and debated issue. The elephant suckling house has a lot to offer regarding the application of nature related elements such as natural ventilation and natural lighting as resorts to less dependency on modern technologies and facilities. Efforts on preserving the style and meaning of this house style should be doubled that can be achieved through awareness in printed materials as well as digital format.

\section{Objectives and methodology}

Objectives of a research are known to guide direction of how the research should take place. They point out the issues that matter most to the research. The objectives of this research are mainly to stress the importance of recording the remaining suckling elephant houses in the northern region of the Peninsular 
Malaysia namely Penang, Kedah and Perlis. Most of the recording and collection of information for the database are produced in hard copies and digital format. The objectives are as follows:

a. To identify the interior space planning of the suckling elephant houses for their functions

b. To explore the philosophy that is related to the interior space planning, the surrounding environment as well as the functions

c. To examine the cultural influences on the interior space planning and the functions of the detail embellishments and the philosophy associated with them

d. To document the research via digital format as part of creating awareness of this style of architecture

The research methodology is divided into five stages. Some of the processes run concurrently with others due to their close vicinity to the running activities or requiring some methods to be applied at the same time. The first stage sees the reviewing of the existing literature on the suckling elephant house. The importance of the configuration of this house has to be taken into consideration for the understanding of the interior space planning. Other related literature will look into Malay cultural issues that comprise of customs and traditions relating to building a house. It is known that any culture in the world has a ritual that is related to building a house. Thus information acquired to all cultural related literature will be used to relate to the suckling elephant house. These additional sources are specifically in Malay culture and other influences that could be found in Malaysia. Balik Pulau, Penang; vicinity of Alor Setar, Kedah; and vicinity of Kangar and Arau, Perlis are the locations for the field work. These are the areas where some suckling elephant houses still exist though some of them have seen some modifications due to the requirements of the owners. Pilot study identifies specific houses in these areas before further work take place. The identification of the suckling house period follows closely the design that has been featured in articles by a few architects. This research method involves some experts on the traditional Malay house with the structured interview as well as the owners of the identified suckling elephant houses through non-structured interview. This process runs simultaneously with the visual data collection and video taping processes. These steps are focussed on the house usage by the owners and their perception of the detail embellishments of the interior of the house while from the experts; the interviews are focussed on construction and space planning of the house. Visual data collection is the collection of evidence of the elephant suckling house in their current state which is then compared to the original design of the house. The data collection method uses photographs, slides and videos to capture the image in relating them to the findings of the cultural philosophy, customs and rituals. Images are still and moving images to capture the lifestyle of the dwellers of this type of house and decorative details incorporated into the house. The still images of the interior spaces of the suckling elephant house are transformed into working drawings and are analysed in terms of space planning. The working drawing on the detail embellishments are undertaken to create a data base with connection to the specific house to the location. This particular method can be cross referenced 
against the cultural issues finding in determining the hidden meaning behind the interior space planning and the detail embellishments. All data acquired and collected from the field work are analysed for better understanding of the research. This is done while relating back to the objectives of this research. Visual data is strengthened with the analysis from the field work before documenting it into a written format. The documentation presents a better understanding of the suckling elephant house.

\section{The Suckling Elephant House}

Physically, the suckling elephant house is a two-structure form that resembles a baby elephant suckling its mother but on the whole it is divided into three compartments. It comprises of a kitchen, a smaller version of the structure, separated by selang (figure 5), the passageway that connects to the rumah ibu, the biggest structure of the two [4]. Every component has specific and different functions although they are interconnected by passageway. The unique functions, divided into domains, communal and personal spaces, of these components contribute to the creation of the suckling baby elephant house.

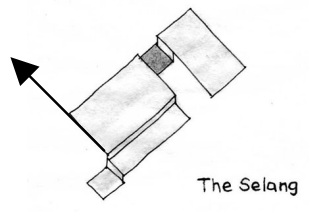

Figure 5: Selang, the middle portion of the house.

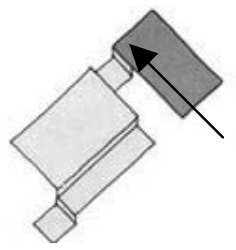

Figure 6: Kitchen.

The kitchen (figure 6) portrays a difference between the two structures by a drop in its floor level and the ridge of its roof.

All these spaces have specific functions and often divided into the domains of men and women (figure 7). Most active areas for the women are the kitchen and the passageway (figure 8) while for men the area is the front of the house, the veranda. The main form of the house indicates of a communal space where all community activities take place. The front space of the house is where guests are received and will be brought into the main area where more formal functions take place (figure 9).

Externally, the suckling elephant house is a construction that combines physical and psychological factors [5]. It takes priority of the location and the climate that houses the structure (figure 10). The design for the house always responds to the climate where orientation of the sun plays an important role in locating the house. Controlling the direct solar radiation is vital while controlling glare from the open skies and surroundings by ample overhangs also doubles as a protection against rain. Most of the time, this house is built with greenery and plantations surrounding it to cool the temperature that envelops the house. Often enough these trees are fruit trees, spices and herbal gardens that provide food supplies for the house owners 


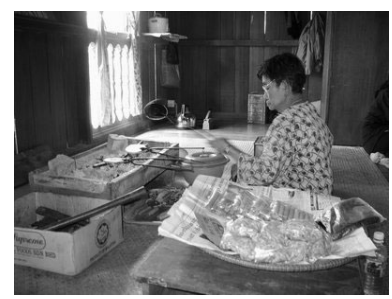

Figure 7: Rear portion, a woman's domain.

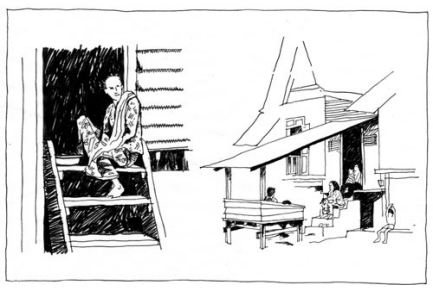

Figure 8: $\quad$ Active areas - at the rear of the house (a place to execute daily chores by the women folks).

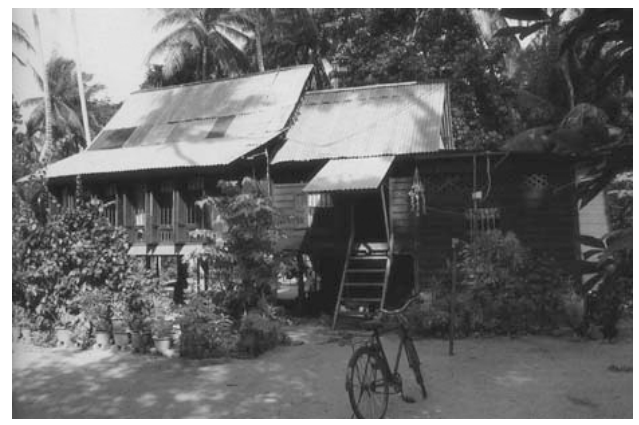

Figure 9: External outlook of a suckling elephant house.

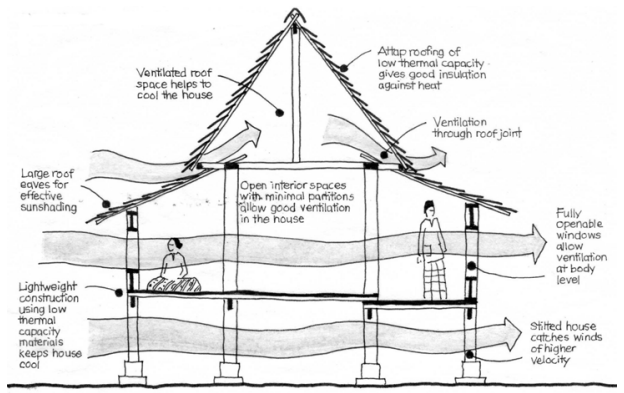

Figure 10: External environment of a typical traditional Malay house.

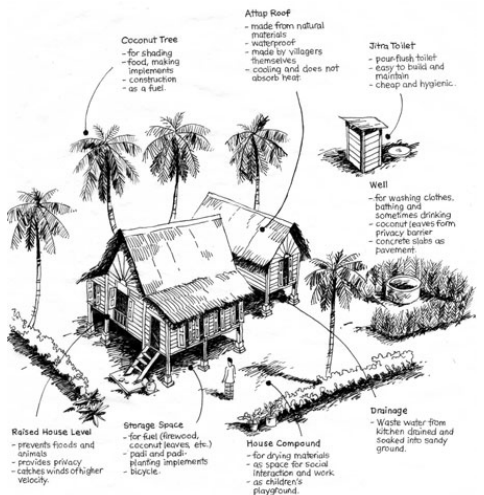

Figure 11: Physical and psychological factors affecting the design.

Ventilation is also important to provide adequate cooling effect while reducing the impact of humidity for the tropical setting requires methods for 
such effect (figure 11). Thus the house form constructed complies with the design that is influenced by the weather [6]. The house design sees that the traditional way of constructing it is always built on stilts or columns to reduce humidity as well as to provide natural ventilation and to avoid flood. At times the house on stilts provides protection from wild animals as most of these houses are built close to the forested areas while keeping the interior spaces dry during rainy season [7]. Lightweight material (figures 12 and 13) is used for the walls to avoid heat retention while roof material is made of nipah palm fronds that provide good insulation against heat. Internally, the house designed is not just for personal use to shelter families but also a place for communal activities, a gathering space for comfort and peace. The breakdown of the interior space planning iterates the various functional spaces. However, all of these spaces function with no definite boundaries. Only the activities can determine the use of the spaces (i.e. cooking - kitchen, communal activities - main area). The invisible borders create an openness of the interior of the house thus making the internal part seems big and airy. Since there is no ceiling constructed, the roof structure is left open directly to the underside of the roof. Spacious interior is created with almost a double volume due to the open roof configuration. This situation in the interior design of the suckling elephant house provides a cool interior in tropical climes that is governed by sun heat, radiation, rain, wind and humidity. The components of the suckling elephant house go further with not only providing the basic shape and construction of a house but also displaying a lot of embellishments that function just as importantly as the main structure of the house.

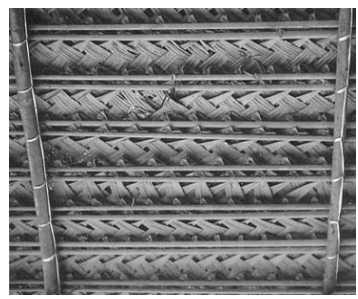

Figure 12: Nipah palm fronds for roof material.

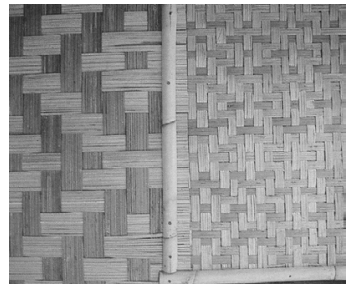

Figure 13: Bamboo for lightweight wall.

\section{Embellishments, symbolism and identity}

The identity of the suckling elephant house reflects the details that are involved in the creation of a holistic construction. The details are heavily laced with customs, traditions, rituals and philosophies hence the embellishments. Although simplicity is the utmost goal for constructing the suckling elephant house, the embellishments are ornate thus giving pleasant aesthetical values. As all of the embellishments motifs are derived from nature, they reflect the sensitivity and observation of the Malay people of respecting the environment [8]. The Malay 
people have gone through various cultural influences namely beginning from the animism, Hindu-Buddhism, Islam and Western periods [9]. These various influences change are visible in the embellishments which in one house design, the interlace meanings can be found. The ornate air vent functions as an opening to allow natural ventilation to pass through to cool the interior of the house. Its design will always be one of the Malay traditional flowers motifs derived from flowers such as rose (mawar - rosa spp), bunga tanjung (mimosops elengi L), tropical gardenia (bunga china - gardenia augusta), tropical magnolia (bunga cempaka - michelia champaca) (figure 14), frangipani (bunga kemboja plumeria acuminata) (figure 15), ylang ylang (bunga kenanga - canagium orodatum)) (figure 16) and jasmine (bunga melur - jasminum sambac) (figure 17) motifs [10]. These flowers are considered the sacred flowers in the Malay culture [11].

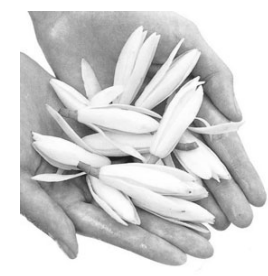

Figure 14: Tropical magnolia.

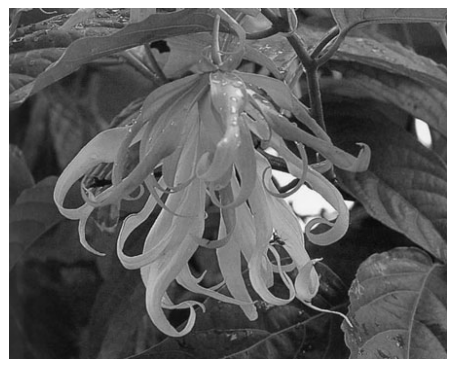

Figure 16: Ylang ylang.

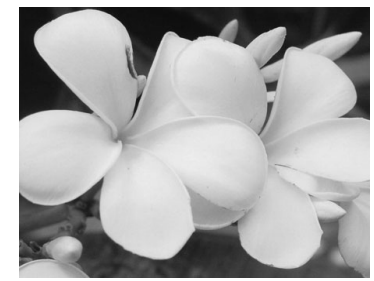

Figure 15: Frangipani.

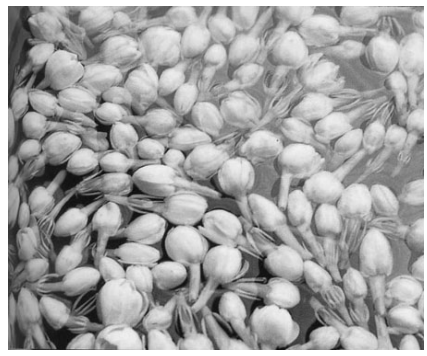

Figure 17: Jasmine.

It is believed that the air passing through the opening vents smells like the flowers that the motifs have been carved and featured in the air vents [12]. The same case applies to other type of embellishments (figures 18 and 19).

The suckling elephant house displays a unique understanding of traditional Malay customs and rituals. It is shown that the embellishments found in the suckling elephant house are constructed for the aspects of air ventilation, sun shading devices, aesthetical reasons and security [13]. Although the embellishments are seen as traditional art forms but they are functional art forms to support the existence of the suckling elephant house. The detailed motifs on the embellishments are basically patterns derived from plants or flora, stylised animals or fauna, geometrical or arabesque, food and court objects [14]. The 


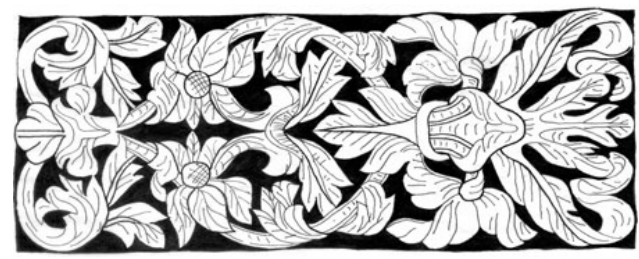

Figure 18: Ornate embellishment based on a flower motif.

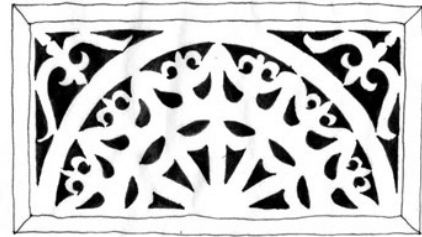

Figure 19: Flower motifs for air vents.

symbolism that involves with any type of traditional Malay house often refers to the application of materials according to instinct [15]. This is true with the case of the suckling elephant house. Nature and the environment become the reference point for construction materials and at the same time the examples for embellishments in making the houses more aesthetically pleasing [16]. However, the reference point only features a simple appearance yet effective with the design of the details that contribute to the authenticity of its design. The details in totality give birth to the high quality of display of house construction and reflecting the Malay life style that is full of traditions and spiritual beliefs [17]. In this humble design and construction, a lot of information on designing related to nature and designing with nature is tabled. Methods, details and processes from the past can be reused as they have succeeded in blending in nature. Above all, this design has shown that human kind has coexisted with nature with the humans respecting nature to ensure comfort for generations to come in their house construction.

\section{Conclusion}

The suckling elephant house though humble in its appearance has shown a house construction that is intelligent and smart in responding to nature and its surroundings. The analysis of the facts of the suckling elephant house that incorporated traditional cultural issues such as philosophy, traditions, rituals and customs have resulted in the outcomes as follows:

- An understanding of interior space planning in a traditional Malay house according to functions.

- A deeper comprehension on the application of detail embellishments in relation to their function and cultural requirements.

- A comprehension on the interior space layout in relation to sustainable home design and can be used further as comparison to modern design dwellings.

- A deeper understanding of the traditional construction of a traditional Malay house according to rituals, customs and traditions.

- An understanding of the requirements of this house design for construction in specific environments and climates.

This paper has shown that the heritage and culture that are represented in the suckling elephant house is a treasure that has been passed on through 
generations. However, the culture is dying out due to the modernisation and new technology in building construction. The lack of interest in this type of architecture especially among the young generations ensures the demise of the knowledge. The suckling elephant house outlines all the rules about designing in and with nature. It has also shown that mankind can coexist with nature that perpetuates their existence. The heritage and culture found in this simple house are more than meet the eyes. The suckling elephant house is the embodiment of the Malay culture starting from its uncomplicated beginning to a certain life standard finishing. It features knowledge that tells stories of by gone eras through its construction, embellishments, interior space planning, materials, form and shape. Most important of all, the suckling elephant house has put forward an identity that is intelligent in design and in combining traditional customs, rituals and philosophies in every element of the form. It is a house that displays design sustainability with aspects of economy, social and environmental as the prime factors that at the end creates its character and identity in cause that is full of history and cultural elements.

\section{References}

[1] The Encyclopaedia of Malaysia Architecture. Chen Voon Fee (ed.). (1998). Singapore: Archipelago Press.

[2] The Traditional House Architecture of Malaysia. Zaharan Mat Jusin \& Mohamad Isa Irin (eds.). (2000). Melaka: PMCT.

[3] Hanafi, Z. (1999). Siri Lukisan Terukur Rumah Traditional Melayu diPulau Pinang. Kulim: Amber-Solara.

[4] The Encyclopaedia of Malaysia Architecture. Chen Voon Fee (ed.). (1998). Singapore: Archipelago Press.

[5] Yatim, M.O. (1989). Warisan Kesenian Dalam Tamadun Islam. Kuala Lumpur: Dewan Bahasa dan Pustaka.

[6] Hanafi, Z. (1996). Pembinaan Bangunan Traditional Melayu. Kulim: Amber-Solara.

[7] Killmann, Wulf; Tom Sickinger \& Hong Lay Thong. (1994). Restoring \& Reconstructing The Malay Timber House. Kuala Lumpur: FRIM.

[8] Bahauddin, A. (1999). Contemporary Malaysian Art: An Exploration of the Songket Motifs. PhD. Thesis. Sheffield: Sheffield Hallam University.

[9] Ahmad Dawa, M.N. (1995). The Symbolism of Batik from Kelantan, Malaysia; Its Origin and Transformation. $\mathrm{PhD}$ Thesis. Manchester: Manchester Metropolitan University.

[10] Zakaria, M. and Mohd, M.A. (1993). The Traditional Malay Medicine Plants. Kuala Lumpur: Fajar Bakti.

[11] Osman, M.T. (1988). Mythical Elements in Malay Historiography. Bunga Rampai: Aspects of Malay Culture. Kuala Lumpur: Dewan Bahasa \& Pustaka.

[12] Jamal, S.A. (1992). Rupa \& Jiwa. Kuala Lumpur: Dewan Bahasa dan Pustaka. 
[13] Hanafi, Z. (1999). Siri Lukisan Terukur Rumah Tradisional Melayu di Pulau Pinang. Kulim: Amber-Solara.

[14] Bahauddin, A. (1999). Contemporary Malaysian Art: An Exploration of the Songket Motifs. PhD. Thesis. Sheffield: Sheffield Hallam University.

[15] Snodgrass, Adrian. (1985). The Symbolism of the Stupa. New York: Southeast Asia Program.

[16] Deraman, A. A. (1994). Masyarakat dan Kebudayaan Malaysia. ed. 2. Kuala Lumpur: Cahaya Pantai.

[17] Mohamed, A. (1984). Falsafah dan Pemikiran Orang-orang Melayu: Hubungannya Dengan Islam dan Kesenian. Kuala Lumpur: Kementerian Kebudayaan, Belia dan Sukan. 